\title{
Telerehabilitation in heart failure patients: The evidence and the pitfalls
}

Ewa Piotrowicz, Massimo F. Piepoli, Tiny Jaarsma, Ekaterini Lambrinou, Andrew J. S. Coats, Jean-Paul Schmid, Ugo Corra, Piergiuseppe Agostoni, Kenneth Dickstein, Petar M. Seferovic, Stamatis Adamopoulos and Piotr P. Ponikowski

\section{Journal Article}

\section{Tweet}

N.B.: When citing this work, cite the original article.

Original Publication:

Ewa Piotrowicz, Massimo F. Piepoli, Tiny Jaarsma, Ekaterini Lambrinou, Andrew J. S. Coats, Jean-Paul Schmid, Ugo Corra, Piergiuseppe Agostoni, Kenneth Dickstein, Petar M. Seferovic, Stamatis Adamopoulos and Piotr P. Ponikowski, Telerehabilitation in heart failure patients: The evidence and the pitfalls, International Journal of Cardiology, 2016. 220, pp.408-413. http://dx.doi.org/10.1016/j.ijcard.2016.06.277

Copyright: Elsevier

\section{http://www.elsevier.com/}

Postprint available at: Linköping University Electronic Press

http://urn.kb.se/resolve?urn=urn:nbn:se:liu:diva-131872

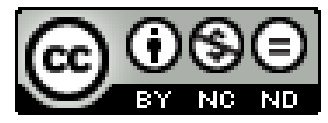




\section{Telerehabilitation in heart failure patients: the evidence and the pitfalls}

Ewa Piotrowicz* MD $^{1}$, Massimo F Piepoli MD, PhD, FESC ${ }^{2}$, Tiny Jaarsma $\mathrm{PhD}^{3}$, Ekaterini Lambrinou $\mathrm{PhD}^{4}$, Andrew J S Coats, DM, D.Sc ${ }^{5}$, Jean-Paul Schmid MD, FESC ${ }^{6}$, Ugo Corrà $\mathrm{MD}^{7}$, Piergiuseppe Agostoni MD, FESC ${ }^{8}$, Kenneth Dickstein MD, PhD, FESC ${ }^{9}$, Petar M. Seferović MD, PhD, FESC ${ }^{10}$ Stamatis Adamopoulos MD, PhD, FESC ${ }^{11}$, Piotr P Ponikowski $\mathrm{MD}, \mathrm{PhD}, \mathrm{FESC}^{12}$

1. Telecardiology Center, Institute of Cardiology, Warsaw, Poland

2. Heart Failure Unit, Cardiology, G da Saliceto Hospital, Piacenza, Italy

3. Faculty of Health Sciences, University of Linköping, Linköping, Sweden

4. Cyprus University of Technology, Cyprus

5. Academic Vice-President, Monash University, Melbourne, Australia and University of Warwick, Coventry, UK

6. Cardiology Clinic, Tiefenauspital, Bern University Hospital, Bern Switzerland

7. Cardiology Division, IRCCS Fondazione 'S. Maugeri', Centro Medico e di Riabilitazione di Veruno, Via per Revislate 13, 28010 Veruno, NOVARA, Italy

8. Centro Cardiologico Monzino, IRCCS, Milano, Italy

9. University of Bergen Stavanger University Hospital Stavanger, Norway

10. Polyclinic of the Clinical Centre of Serbia, and Department of Internal Medicine Belgrade University School of Medicine.

11. Heart Failure-Transplant Unit, Onassis Cardiac Surgery, Athens, Greece.

12. Department of Heart Diseases, Faculty of Health Sciences, Wroclaw Medical University Military Hospital, Wroclaw, Poland.

*Corresponding author: Ewa Piotrowicz, MD, PhD

Telecardiology Center, Institute of Cardiology, Alpejska 42 , 04-628 Warsaw, Poland tel. +48223434664, fax.+48223434519, e-mail: epiotrowicz@ikard.pl 


\begin{abstract}
Accessibility to the available traditional forms of cardiac rehabilitation programmes in heart failure patients is not adequate and adherence to the programmes remains unsatisfactory. The home-based telerehabilitation model has been proposed as a promising new option to improve this situation. This paper's aims are to discuss the tools available for telemonitoring, and describing their characteristics, applicability, and effectiveness in providing optimal long term management for heart failure patients who are unable to attend traditional cardiac rehabilitation programmes. The critical issues of psychological support and adherence to the telerehabilitation programmes are outlined. The advantages and limitations of this long term management modality are presented and compared with alternatives. Finally, the importance of further research, multicentre studies of telerehabilitation for heart failure patients and the technological development needs are outlined, in particular interactive remotely controlled intelligent telemedicine systems with increased inter-device compatibility.
\end{abstract}

Key words: telerehabilitation, heart failure, exercise training

\title{
List of abbreviations:
}

American Heart Association

AHA

Cardiac rehabilitation

CR

Cardiovascular implantable electronic devices

CIEDs

European Society of Cardiology

ESC

Heart failure

HF

Quality of life

QoL 


\section{Introduction}

In Europe, the estimated number of patients suffering from heart failure (HF) lies between 6.5 and 10 million [1]. A rising number of HF patients combined with an increased frequency of HF related hospitalization and rehospitalization combine to place financial stresses not only on health care systems, but even for entire national budgets. The challenge of the future is the effective organization of holistic management for HF patients, as suggested in guidelines of both the European Society of Cardiology (ESC) and the American Heart Association (AHA) [1,2]. The benefits of exercise training for HF patients are well documented and unquestionable. In patients with stable HF exercise training can relieve symptoms, improve exercise capacity and quality of life (QoL) and reduce disability, hospitalization and mortality [1-5]. Cardiac rehabilitation (CR) for HF patients is now widely recognized as safe, with benefits easily surpassing any related risk [1-6]. Therefore, current guidelines strongly recommend exercise training in all stable HF patients [1-3]. Although exercise training is a class I, level of evidence A recommendation, it remains poorly implemented in everyday clinical practice. According to a recent European Survey, less than 20\% of HF patients participate in hospital-based and/or outpatient CR programmes [7]. There are numerous factors which hinder the participation in either hospital-based or out-patient CR: logistics (commuting problems), resistance to leaving home, anxiety and depression, difficulties of incorporating hospital based and outpatient exercise trainings into daily life, etc.[8]. That is why the possibility of transferring the location of CR to the patient's home creates a real opportunity to overcome these and other obstacles and to enhance the availability of the important core components of CR. It is nevertheless crucial to ensure training programmes at home are delivered with a high level of safety and psychological comfort. According to most guidelines, exercise training in moderate and high risk patients should be initially supervised. In particular, high risk patients need to be monitored "until safety is established” and patients feel confident enough to continue the training by themselves [2].

Modern technological and telemedical advances have enabled physicians and other health care providers to monitor patients remotely $[9,10]$. Methods of remote monitoring vary from the ‘simple' telephone support to external or implantable devices (Table 1)[9-15]. They are concordant with current AHA guidelines, which state that: ”The use of trans-telephonic ECG monitoring at home has been suggested as a substitute for outpatient visits to the clinic."[2]. The indications for the use of cardiovascular implantable electronic devices (CIEDs) are constantly being expanded and more and more patients are being implanted with such 
devices. Thanks to the homemonitoring option in CIEDs various physiological parameters can be remotely monitored [15-18]. The recent data from IN-TIME study showed that automatic, daily, implant-based, multiparameter telemonitoring can significantly improve clinical outcomes for HF patients. Such telemonitoring can be considered feasible and effective and many experts now feel should be used in routine clinical practice[19].

Another valid, yet still futuristic option could be monitoring HF patients via hemodynamic devices (left atrial pressure, pulmonary artery pressure) but such devices remain in the research phase at the present time[20,21].

The data from telephone support, external monitoring devices, home monitoring CIEDs and implantable haemodynamic devices can be used in telecare and may provide a basis for safe telerehabilitation (Table 1). The safety of such treatment is due in part to the fact that telemedicine is an effective tool to enable the physician to assess, and by early advice and intervention, maintain patient stability through remote supervision during exercise training. The present article outlines the opportunities offered by telemedicine in terms of telerehabilitation for HF patients.

\section{Telecare in HF patients: Definition}

Telecare in HF patients can be defined as monitoring which consists of the transmission of symptoms, signs and/or biological or physiological data from a remote location to another location for data interpretation and decision-making[9,22]. The most basic form of telecare is structured telephone support, in which providers (nurses) schedule routine telephone contacts with patients for ongoing assessment.

Telecare also encompasses the concept of telemonitoring, in which symptoms (chest pain, fatigue, breathlessness, oedema etc) and/or physiological data (such as heart rate, ECG, weight, blood pressure) derived from external monitoring devices, home monitoring CIEDs and/or implantable hemodynamic devices are transferred automatically to a healthcare provider via a wireless or broadband connection, with targeted follow-up triggered by variances that exceed preset thresholds. Telemonitoring can be conducted manually or automatically. The manual version means that the data is assessed and interpreted by health care professionals. The automated version implies that the data transferred to the monitoring center is assessed by specialized software, generating alarms for health care professionals and/or decision support to optimize treatment.

In addition to telemonitoring, telecare also includes teleassessment (active remote assessment), telesupport (e.g. supportive televisits by nurses, psychological support), 
teletherapy (interactive therapy), telecoaching (support and instruction for therapy), teleconsulting and telerehabilitation. This last concept is defined as a supervised remote comprehensive CR [22,23], and it includes the telecare and telesupervision of exercise training.

\section{The telemonitoring process}

\section{Methods of delivery}

The technological advances of recent decades have led to the development of the following principal methods of delivering telemedical care: real-time (synchronous), store-and-forward (asynchronous), and hybrid systems. In synchronous systems, the patient and the telecare provider need to be available at the same time; asynchronous methods do not require this [24]. Data transfer In order to obtain and transfer data on a patient's condition the following technologies can applied in telemedicine: portable medical imaging devices, personal digital assistants (PDAs) such as smart phones, and many types of wireless communication. The crucial factor for telemedical treatment today is the stable availability of network access, which, in some systems, has reached $99.7 \%$. Specialists distinguish two types of data transfer: the outbound (patient to telemedical center) and inbound (telemedical center to patient) data transfer. The most advanced systems take advantage of automatic algorithms which are capable of evaluating the incoming data, identifying numerous predictors of clinical deterioration as well as prioritizing human contact with patients undergoing telemedical treatment $[9,24]$.

\section{Remote management systems}

These are classified according to specific criteria such as the telemedical system's integration with patients' primary care unit, the data transfer type and the telemedical system's reaction and interaction level (i.e. the ability to make instantaneous decisions). Commonly distinguished system generations are presented [9,24]:

- simple data collection: recording devices, which transfer data to the telemedical center without simultaneous evaluation and intervention to the recorded data

- remote patient management systems (data is transferred and analyzed by the telemedical staff)

- fully integrated remote management systems: an advanced version of the previous system which integrates the recording capacity with the assistance of a telemedical care unit by offering the on-time assistance of an on-duty physician. 


\section{Telerehabilitation systems}

Only a few models of home-based telerehabilitation have been presented to date [10,23-30]. In all, the patients need to preliminary undergo to a training period either in hospital or at home to familiarize themselves with the systems

Heart rate monitoring

Exercise diaries and heart rate monitors are provided and data are recorded in a computer. The telemedical team contacts the patients on a weekly basis via telephone or email to report on their progress. Patients are required to hand in their heart rate monitors and exercise diaries every four to six weeks [25].

\section{Transtelephonic electrocardiographic monitoring}

This system has been tested in a public gym, which was equipped with transtelephonic electrocardiographic monitoring kits. If alarming symptoms were detected, a twelve-lead ECGs of the patient was transmitted by qualified trainers in real time via regular telephone lines and assessed by the medical staff at the telecare unit. After ECG evaluation, the cardiologist contacted the exercise trainer to provide instructions for any required intervention [26].

Tele-electrocardiogram monitoring and supervision using a remote exercise training device In this particular system, special equipment is distributed to the patient. It consists of the following elements: a device for ECG recording, blood pressure measuring and weighing machines, a mobile phone and a mobile phone based data transmission set. Prior to the training session, the patient is requested to answer a series of questions regarding his/her current condition and medications taken. Subsequently, patients would transmit their resting ECG, blood pressure and weight data to the monitoring center and are permitted to begin the training session only if no contraindications are identified. Each set contains the patient's individualized pre-programmed and previously defined training session, exercise duration, breaks and timing of ECG recording. Immediately after the training session, if uneventful, the ECG recording is transmitted to the monitoring centre and analyzed. On the basis of the obtained data, consultants are able to adjust the training workload appropriately or, should the necessity arise, to discontinue the session . The monitoring center receives, stores and analyses patients’ medical data and a follow-up report is generated [23,27-30]. Real time electrocardiographic and voice transtelephonic monitoring of cardiac rehabilitation

In this system patients are given a real-time transtelephonic electrocardiographic transmitter and a headset with earphones and a microphone. The system is capable of simultaneously 
monitoring up to four patients who are encouraged to take part in conference phone calls. It helps them to interact as a group and allows the monitoring staff to conduct teaching and group therapy sessions [31].

Telemonitoring physical activity using movement sensor

Two movement sensors are being commonly used at the moment: accelerometers and pedometers. The main purpose of an accelerometer is to assess and quantify any motion or movement associated with physical activity. They enable consistent, unhindered and continuous monitoring and provide a count value, which describes the intensity, frequency and duration of physical activity. Pedometers by contrast measure the number of steps taken during a day and may be able to provide calculated distance travelled and energy-expenditure values [32-34].

Mobile phone-based applications for rehabilitation

Various applications measuring different movement types are available for mobile phones, PDAs, etc. Some mobile phones are equipped with an accelerometer function, others offer wellness diary software which collects data on patients' physiological state and other medical information. Health care providers can take advantage of web-portals to individualize goal setting and to evaluate the progress of each participant of the telerehabilitation programme. Educational multimedia content can also be transferred to patients and be viewed by them on demand [35,36].

\section{Gaming systems in rehabilitation}

Gaming systems have been developed over the last years and proposed in rehabilitation, for example active video games such as Nintendo Wii Fit. This exercise-based game software transmits the data obtained almost immediately to the Wii console by Bluetooth [37-39]. Only one case analyzing the effect of 12 weeks of Nintendo Wii Fit on daily physical activity of a 74-old patient with chronic HF has been reported . In the course of the study and afterwards, the energy expended by the patient per day, exercise capacity and the motivation to exercise all increased [39]. Although no guidelines for “exergaming” are available, it may play a role in selected patients in the crucial motivation to participate in physical activity, especially among the younger population.

All the above mentioned systems have been proven safe and effective.

\section{Effectiveness of telerehabilitation}

The literature reporting on telerehabilitation is rather scarce and mainly focuses on low risk patients [40-42]. These studies have shown favourable effects resulting from telemonitored 
CR. Some studies have been conducted, yet the groups analyzed were inhomogeneous, i.e. principally low-risk groups but including a few higher-risk patients [26,31]. Only few studies are wholly dedicated to home-based telerehabilitation of HF patients [25,27-30,43]. One of the first studies to assess telerehabilitation in HF patients specifically was that of Smart et al. who described a 35-week home-based CR model initiated 16-weeks after a hospital-based exercise training programme. Patients were provided with heart rate monitors and exercise diaries. They were also offered scheduled telephone and e-mail consultations. This study showed that home rehabilitation based on heart rate monitoring maintained the oxygen consumption improvement achieved during previous rehabilitation in hospital settings, only in patients with HF adherent to the programme [25].

Giallauria et al. assessed the efficacy of telecardiology in improving the effects of CR during 3 sessions weekly for 8 weeks in post-MI patients. The patients were subdivided into three groups (15 each): outpatient CR, home-based CR with telecardiology monitoring and homebased CR without ECG-monitoring (left ventricular ejection fraction were $35 \pm 6 \%, 31 \pm 9 \%$ and $34 \pm 8 \%$, respectively). Physical capacity and exercise duration improvement were comparable in patients trained in an out-patient centre and at home with ECG monitoring. Importantly patients who trained at home without telemonitoring failed to obtain favourable effects [43].

There are two randomized studies evaluating telerehabilitation in HF patients. The first one showed that an 8-week home-based telerehabilitation programme based on walking training provided improvements in physical capacity and quality of life similar to that of a standard outpatient rehabilitation programme based on cycloergometer training [27]. The second one, recently published, demonstrated that an 8-week home-based telemonitored Nordic walking training programme was well accepted, safe, effective and had high adherence among HF patients, including those with CIEDs [30].

\section{Safety of telerehabilitation in HF patients}

A crucial issue regarding home-based telerehabilitation is the best way to ensuring the safety of HF patients who participate [5-7]. It is crucial because these patients will lack the close and direct contact with medical staff that in-hospital or outpatient programmes can offer.

Published data have to date not reported major adverse events or complications during telerehabilitation, such as deaths or malignant arrhythmias [25-31,40,43]. Nevertheless, some minor events have been noted. Smart et al. reported one patient with a nonfatal myocardial infarction, one with a stroke, and another with a brief hospitalization because of worsening 
HF. The authors do not specify whether these events took place during or after the training session[25]. Similarly, Piotrowicz et al. reported on three episodes of paroxysmal atrial fibrillation, including one asymptomatic event diagnosed through ECG monitoring. These arrhythmias had no relation to exercise training and occurred while performing routine daily activities. They led to the temporary suspension of the training programme, yet when sinus rhythm and clinical stabilization were restored, the patients continued their exercise training $[27,28]$. In another study the same authors describe that a low percentage of patients $(5.3 \%)$ reported skin reactions caused by the electrodes [30]. The data available so far suggest that the benefits of regular physical training outweigh the risks it may entail. Table 2 lists factors which influence the safety of telerehabilitation.

\section{Psychological aspects of telerehabilitation - quality of life, depression and anxiety.}

Heart failure progression is usually associated with a decline not only in physical functioning but also in psychological well-being, with depression becoming more prevalent. Both physical and psychological deterioration common and have an unfavourable effects on patients' daily life activities, QoL and eventually their hospitalization and mortality rates [44]. Patients with HF are more reluctant to undertake exercise than to comply with other recommendations (e.g. diet and medication) and are also more likely to adhere to a home-based exercise programme than to a supervised one [45]. Telerehabilitation may serve as a helpful strategy for continuing monitoring and management of a patient allowing face-to-face intervention, including relatives (e.g. spouse) in a familiar environment and as part of the everyday way of life. Reducing depressive feelings which work as a barrier for exercise training, may enhance exercise adherence and ultimately health-related QoL [45].

To date only a small number of studies have been dedicated to studying the psychological aspects of telerehabilitation [25,27,29,30]. Smart et al. showed that QoL and depression improvements achieved during a 16-week outpatients programme were maintained in the adherent HF patients during 35-week home-based telerehabilitation extension [25]. Giallauria et al. reported an improvement in anxiety levels and a trend to limiting depression in the telerehabilitation group compared to the group which exercised at home without telemonitoring. In this study the evaluation of QoL demonstrated no change or improvement in telerehabilitated patients in contrast to worsening of QoL parameters in most patients rehabilitated at home without telemonitoring [43]. Piotrowicz et al. assessed QoL changes in HF patients during 8-weeks of home-based telemonitored CR versus standard outpatientbased CR. This study demonstrated that in HF patients telerehabilitation provided a similar 
improvement in total QoL index compared to standard rehabilitation; yet there were differences in QoL subscales. Patients who underwent home-based telerehabilitation recorded an improvement mainly in the mental categories. In contrast patients in the standard rehabilitation group improved their general physical well-being [29]. Telerehabilitated patients, apart from benefiting from exercise training, might receive parallel psychological telesupport and teleassistance from the telemonitoring team (nurse, physician, physiotherapist) $[25,27,29,30]$. Patients might also become more independent in performing their everyday tasks, their mental and physical condition might improve, and their life might become less affected by the limitation resulting from HF, although as yet these remains speculative possibilities until the appropriate studies are performed.

It is noteworthy that cardiac telerehabilitation programmes extended their goals towards longer durations of exercise participation, along with improved QoL, reduced anxiety and depressive symptoms by involving health professionals (e.g. doctors, nurses, physiotherapists) $[46,47]$. They also focus on prompt patient-centered interventions, promoting self-care practices and maintaining high-level patient and clinician interaction [48].

\section{Acceptance and adherence to telerehabilitation (overcoming common barriers to exercise training)}

Several factors interact to influence adherence to exercise, yet there is no clear set of variables that have been established to help identify people who are likely to exercise, keep exercising or attend exercise programmes [49]. Barriers to exercise intervention adherence include:

- $\quad$ the severity of the disease (e.g. a high symptom burden),

- $\quad$ social and economic issues (e.g. inadequate support from relatives or financial resources to attend fitness centres),

- $\quad$ the health care team or health care system (e.g. no place in a rehabilitation programme or no reimbursement) [8,50],

- $\quad$ for some patients the lack of direct contact or face-to-face meetings might decrease their adherence,

- $\quad$ problems with technology and not possessing the technical expertise to establish systems and to troubleshoot information and communication technologies .

Despite these inconveniences, the published data which evaluates adherence to, and acceptance of telerehabilitation are promising both among low-risk and high-risk patients $[27,30,42,43]$. Patients' adherence to therapy can often be improved by resolving the problems related to these factors [51]. Other successful strategies may include: 
- cognitive behavioral strategies such as those used in motivational interviewing, and strategies that enhance patient self-efficacy for exercise, patient education and support from peers, family and friends [8],

- adapting an exercise programme to patients’ preferences and eliciting support from others,

- allowing patients to choose the best programme for their needs and cicumstances [50],

- eliminating the need to travel and enabling patients to choose the most suitable training modality.

Published data have demonstrated that patients will accept several models of home-based telerehabilitation. In the majority of cases they did not report any significant problems related to operating the telemonitoring equipment. They understood the need for interactive collaboration with the monitoring centre, enjoyed it and were very satisfied with the telemonitoring team support [27,29,41-43].

Giallauria's results demonstrated that adherence to telerehabilitation was $100 \%$ in comparison to $87 \%$ in hospital rehabilitation and home-based rehabilitation without telemedicine[43]. In the study of Piotrowicz et al. all patients undergoing home-based telemonitored rehabilitation completed their 8-week exercise programme in contrast to $20 \%$ of ambulatory rehabilitated patients who discontinued rehabilitation[27]. Also in another study by the same authors it was reported that all patients completed an 8-week home-based telemonitored Nordic walking training. The majority $(94,7 \%)$ of the patients were adherent and only 5.3\% were partially adherent [30]. All authors reporting on cardiac telerehabilitation programmes agree that the adherence to telerehabilitation seems to be equal to or superior to the adherence to out-patient CR [25-31].

\section{Advantages and limitations of telerehabilitation}

Every new technology and methodology, apart from having benefits, also has certain limitations. Table 3 lists the advantages and disadvantages of home-based telerehabilitation [25-31,40-43,52].

\section{Conclusions}

The main challenge of CR at the moment is the need to overcome its currently unsatisfactory accessibility. In doing so there is a need to even out regional differences in availability and uptake. A promising solution to these problems seems to be home-based telerehabilitation. According to the available evidence, it is clear that such treatment is technologically and logistically implementable and thus offers an effective and safe way of rehabilitation accepted 
by patients and the caregiver-team. Various telerehabilitation models based on different technological, methodological and logistic solutions are available. Nevertheless, there are but a few reliable CR models for HF patients. This specific group of patients requires individualized programmes, procedures and the monitoring of numerous symptoms and parameters referred to as “tailored comprehensive home-based telerehabilitation”. Although specialized medical equipment for this modality is being constantly developed, the most promising solution seems to be the creation of mobile phone applications, since they can be commonly used thanks to mobile Internet technologies and their increasing accessibility. As of now there exist no studies evaluating the cost-effectiveness of home based telerehabilitation in HF patients, yet there are suggestions that the costs of rehabilitation might be reduced thanks to this method and its further development. The next step in technological research should be the creation of interactive remotely controlled intelligent system for telerehabilitation and establishing a platform to ensure compatibility between different devices applied in telemedicine.

All the HF patient home-based programmes should offer comprehensive CR and, thanks to the application of advanced technologies, are capable of providing care and assistance in different settings while patients are away from their medical unit.

\section{Future challenges}

The future challenge for clinicians involved in training programs for patients with HF is to create a multicenter research collaboration dedicated to home-based telerehabilitation in HF patients. This trial should be designed to evaluate the utility and safety of this model of rehabilitation in routine clinical care, including its effectiveness, degree of patient adherence and acceptance as well as cost-effectiveness. The results might permit the introduction of telerehabilitation programmes into guidelines as an alternative to outpatient cardiac rehabilitation for a selected group of patients with HF. 


\section{References}

1.Ponikowski P, Voors AA, Anker SD, et al. 2016 ESC guidelines for the diagnosis and treatment of acute and chronic heart failure . The Task Force for the diagnosis and treatment of acute and chronic heart failure of the European Society of Cardiology. Developed with the special contribution of the Heart Failure Association (HFA) of the ESC. Eur Heart J. 2016; doi:10.1093/eurheartj/ehw128

2.Fletcher GF, Ades PA, Kligfield P, Arena R, Balady GJ, Bittner VA, Coke LA, Fleg JL, Forman DE, Gerber TC, Gulati M, Madan K, Rhodes J, Thompson PD and Williams MA Exercise Standards for Testing and Training: A Scientific Statement From the American Heart Association. Circulation. 2013;128:873-934;

3.Piepoli MF, Hoes AW, Agewall S et al. 2016 European Guidelines on cardiovascular disease prevention in clinical practice The Sixth Joint Task Force of the European Society of Cardiology and Other Societies on Cardiovascular Disease Prevention in Clinical Practice (constituted by representatives of 10 societies and by invited experts) Developed with the special contribution of the European Association for Cardiovascular Prevention \& Rehabilitation (EACPR). Eur Heart J 2016 doi:10.1093/eurheartj/ehw106

4. Piepoli MF, Conraads V, Corra U et al. Exercise training in heart failure: from theory to practice. A consensus document of the Heart Failure Association and the European Association for Cardiovascular Prevention and Rehabilitation. Eur J Heart Fail, 2011;13:347-357.

5. PiepoliMF, Davos C, Francis DP, et al. Exercise training meta-analysis of trials in patients with chronic heart failure (ExTraMATCH). BMJ. 2004;328:189.

6. O’Connor CM, Whellan DJ, Lee KL et al. Efficacy and Safety of Exercise Training in Patients With Chronic Heart Failure HF-ACTION Randomized Controlled Trial JAMA, 2009;301,14:1439-1450

7. Bjarnason-Wehrens B, McGee H, Zwisler AD, Piepoli MF, Benzer W, Schmid JP, Dendale P, Pogosova NG, Zdrenghea D, Niebauer J, Mendes M, Cardiac Rehabilitation Section European Association of Cardiovascular Prevention and Rehabilitation. Cardiac rehabilitation in Europe: results from the European Cardiac Rehabilitation Inventory Survey. Eur J Cardiovasc Prev Rehabil 2010;17:410-418.

8.Conraads VM, Deaton C, Piotrowicz E, et al. Adherence of heart failure patients to exercise: barriers and possible solutions: a position statement of the Study Group on Exercise Training in Heart Failure of the HFA of the ESC. Eur J Heart Fail. 2012;14(5):451-8. 
9. Burke LE, Ma J, Azar KMJ. Current Science on Consumer Use of Mobile Health for Cardiovascular Disease Prevention A Scientific Statement From the American Heart Association. Circulation. 2015;132:00-00. DOI: 10.1161/CIR.0000000000000232. 10. Frederix I, Vanhees L, Dendale P, Goetschalckx K. A review of telerehabilitation for cardiac patients. $J$ Telemed Telecare 2015;21,45-53.

11. Inglis SC, Clark RA, McAlister FA, Stewart S, Cleland JG. Which components of heart failure programmes are effective? A systematic review and meta-analysis of the outcomes of structured telephone support or telemonitoring as the primary component of chronic heart failure management in 8323 patients: Abridged Cochrane Review. Eur J Heart Fail. 2011 Sep;13(9):1028-40.

12. Koehler F, Winkler S, Schieber M, Sechtem U, Stangl K, Böhm M, Boll H, Baumann G, Honold M, Koehler K, Gelbrich G, Kirwan BA, Anker SD; Telemedical Interventional Monitoring in Heart Failure Investigators. Impact of remote telemedical management on mortality and hospitalizations in ambulatory patients with chronic heart failure: the telemedical interventional monitoring in heart failure study. Circulation. 2011 3;123(17):1873-80.

13. Koehler F, Winkler S, Schieber M, Sechtem U, Stangl K, Böhm M, de Brouwer S, Perrin E, Baumann G, Gelbrich G, Boll H, Honold M, Koehler K, Kirwan BA, Anker SD. Telemedicine in heart failure: pre-specified and exploratory subgroup analyses from the TIMHF trial. Int J Cardiol. 2012 Nov 29;161(3):143-50.

14. Dendale P, De Keulenaer G, Troisfontaines P, Weytjens C, Mullens W, Elegeert I, Ector B, Houbrechts M, Willekens K, Hansen D. Effect of a telemonitoring-facilitated collaboration between general practitioner and heart failure clinic on mortality and rehospitalization rates in severe heart failure: the TEMA-HF 1 (TElemonitoring in the MAnagement of Heart Failure) study. Eur J Heart Fail. 2012 Mar;14(3):333-40.

15. Dubner S, Auricchio A, Steinberg JS, Vardas P, Stone P, Brugada J, Piotrowicz R, Hayes DL, Kirchhof P, Breithardt G, Zareba W, Schuger C, Aktas MK, Chudzik M, Mittal S, Varma N. ISHNE/EHRA expert consensus on remote monitoring of cardiovascular implantable electronic devices (CIEDs). Ann Noninvasive Electrocardiol. 2012 Jan;17(1):36-56.

16. Sack S, Wende CM, Nägele H, Katz A, Bauer WR, Barr CS, Malinowski K, Schwacke H, Leyva F, Proff J, Berdyshev S, Paul V. Potential value of automated daily screening of cardiac resynchronization therapy defibrillator diagnostics for prediction of major cardiovascular events: results from Home-CARE (Home Monitoring in Cardiac Resynchronization Therapy) study. Eur J Heart Fail. 2011;13(9):1019-27. 
17. van Veldhuisen DJ, Braunschweig F, Conraads V, Ford I, Cowie MR, Jondeau G, Kautzner J, Aguilera RM, Lunati M, Yu CM, Gerritse B, Borggrefe M; DOT-HF Investigators. Intrathoracic impedance monitoring, audible patient alerts, and outcome in patients with heart failure. Circulation. 2011 Oct 18;124(16):1719-26.

18. Bourge RC, Abraham WT, Adamson PB, Aaron MF, Aranda JM Jr, Magalski A, Zile MR, Smith AL, Smart FW, O'Shaughnessy MA, Jessup ML, Sparks B, Naftel DL, Stevenson LW; COMPASS-HF Study Group. Randomized controlled trial of an implantable continuous hemodynamic monitor in patients with advanced heart failure: the COMPASS-HF study. $J$ Am Coll Cardiol. 2008;18;51(11):1073-9.

19. Hindricks G, Taborsky M, Glikson M, et al. Implant-based multiparameter telemonitoring of patients with heart failure (IN-TIME): a randomised controlled trial. Lancet 2014 (384): 583-590.

20. Abraham WT, Adamson PB, Bourge RC, Aaron MF, Costanzo MR, Stevenson LW, Strickland W, Neelagaru S, Raval N, Krueger S, Weiner S, Shavelle D, Jeffries B, Yadav JS; CHAMPION Trial Study Group. Wireless pulmonary artery haemodynamic monitoring in chronic heart failure: a randomised controlled trial. Lancet. 2011 19;377(9766):658-66.

21. Ritzema J, Troughton R, Melton I, Crozier I, Doughty R, Krum H, Walton A, Adamson P, Kar S, Shah PK, Richards M, Eigler NL, Whiting JS, Haas GJ, Heywood JT, Frampton CM, Abraham WT on behalf of the HOMEOSTASIS Study Group. Physician-directed patient selfmanagement of left atrial pressure in advanced chronic heart failure. Circulation 2010;121:1086-1095.

22. Shaw DK, Heggestad-Hereford JR, Southard DR, et al. American Association of Cardiovascular and Pulmonary Rehabilitation Telemedicine position statement. J Cardiopulm Rehabil 2001; 21: 261-262.

23. Piotrowicz E. How to do: Telerehabilitation in heart failure patients. Cardiol J 2012; 19: 243-248

24. Anker SD, Koehler F, Abraham WT. Telemedicine and remote management of patients with heart failure. Lancet 2011;378, 731-739

25. Smart N, Haluska B, Jeffriess L, et al. Predictors of sustained response to exercise training in patients with chronic heart failure: A telemonitoring study. Am Heart J 2005; 150: 12401247

26. Kouidi E, Farmakiotis A, Kouidis N, et al. Transtelephonic electrocardiographic monitoring of an outpatient cardiac rehabilitation programme. Clin Rehabil 2006; 20: 11001104. 
27. Piotrowicz E, Baranowski R, Bilinska M, et al. A new model of home-based telemonitored cardiac rehabilitation in patients with heart failure: Effectiveness, quality of life and adherence. Eur J Heart Fail 2010; 12: 164-171.

28. Piotrowicz E, Jasionowska A, Banaszak-Bednarczyk M. et al. ECG telemonitoring during home-based cardiac rehabilitation in heart failure patients. J Telemed Telecare 2012; 18: 193197.

29. Piotrowicz E, Stepnowska M, Leszczyńska-Iwanicka K et al. Quality of life in heart failure patients undergoing home-based telerehabilitation vs outpatient rehabilitation - a randomised controlled study. Eur J Cardiovasc Nurs. 2015 Jun;14(3):256-63. doi:

\section{$10.1177 / 1474515114537023$}

30. Piotrowicz E, Zielinski T, Bodalski R et al. Home-based telemonitored Nordic walking training is well accepted, safe, effective and has high adherence among heart failure patients, including those with cardiovascular implantable electronic devices - a randomized controlled study. Eur J Prev Cardiol 2015;22(11):1368-1377.

31. Squires RW, Miller TD, Harn T, et al. Transtelephonic electrocardiographic monitoring of cardiac rehabilitation exercise sessions in coronary artery disease. Am J Cardiol 1991; 67: 962-964.

32. Corder K, Brage S, Ekelund U. Accelerometers and pedometers: methodology and clinical application. Curr Opin Clin Nutr Metab Care 2007, 10:597-603

33. Kaminsky LA, Jones J, Riggin K, Strath SJ. A pedometer-based physical activity intervention for patients entering a maintenance cardiac rehabilitation program: a pilot study. Cardiovasc Diagn Ther 2013;3(2):73-79

34. Jehn M, Prescher S, Koehler K, von Haehling S, Winkler S, Deckwart O, Honold M, Sechtem U, Baumann G, Halle M, Anker SD, Koehler F. Tele-accelerometry as a novel technique for assessing functional status in patients with heart failure: feasibility, reliability and patient safety. Int J Cardiol. 2013 Oct 12;168(5):4723-8.

35.Worringham Ch, Rojek A, Stewart I. Development and Feasibility of a Smartphone, ECG and GPS Based System for Remotely Monitoring Exercise in Cardiac Rehabilitation. PLoS ONE 6(2): e 14669, doi:10.1371/journal.pone.0014669

36.Soares D, Magalhaes S, Viamonte S. Home-Based Programs and Application of New Technologies in Cardiac Rehabilitation. Int J Phys Med Rehabil 2013;1:158. doi: 10.4172/2329-9096.100015. 
37.Nicholson VP, McKean M, Lowe J, Fawcett C, Burkett B. Six Weeks of Unsupervised Nintendo Wii Fit Gaming is Effective at Improving Balance in Independent Older Adults. $J$ Aging Phys Act. 2014 Feb 28.

38. Klompstra LV, Jaarsma T, Strömberg A. Exergaming in older adults: A scoping review and implementation potential for patient with heart failure. Eur J Cardiovasc Nurs 2014 Oct;13(5):388-98. doi: 10.1177/1474515113512203.

39. Klompstra LV, Jaarsma T, Strömberg A. An in-depth, longitudinal examination of the daily physical activity of a patient with heart failure using a Nintendo Wii at home: a case report. J Rehabil Med. 2013;45(6):599-602.

40. Fletcher GF, Chiaramida AJ, LeMay MR. et al. Telephonically monitored home exercise early after coronary artery bypass surgery Chest 1984;86;198-202.

41. Scalvini S, Zanelli E, Comini L, et al. Home-based exercise rehabilitation with telemedicine following cardiac surgery. J Telemed and Telecare 2009; 15: 297-301.

42. Piotrowicz E, Korzeniowska-Kubacka I, Chrapowicka A,Wolszakiewicz J, Dobraszkiewicz-Wasilewska B, Batogowski M, Piotrowski W, Piotrowicz R. Feasibility of home-based cardiac telerehabilitation: Results of TeleInterMed study. Cardiol J 2014;21(5):539-46. doi: 10.5603/CJ.a2014.0005.

43. Giallauria F, Lucci R, Pilerci F. et al. Efficacy of telecardiology in improving the results of cardiac rehabilitation after acute myocardial infarction. Monaldi Arch Chest Dis 2006;66:812.

44. Guck TP, Elsasser GN, Kavan MG, Barone EJ. Depression and congestive heart failure. Congest Heart Fail. 2003;9(3):163-169.

45. Barbour KA, Miller NH. Adherence to exercise training in heart failure: a review. Heart Fail Rev 2008,13(1):81-9

46. Jolly K, Taylor RS, Lip GY et al. A randomized trial of the addition of home-based exercise to specialist heart failure nurse care: the Birmingham Rehabilitation Uptake Maximisation study for patients with Congestive Heart Failure (BRUM-CHF) study. Eur $J$ Heart Fail. 2009,11(2):205-13

47. Piotrowicz E, Piotrowski W, Piotrowicz R. Positive Effects of the Reversion of Depression on the Sympathovagal Balance after Telerehabilitation in Heart Failure Patients. Ann Noninvasive Electrocardiol 2015;Nov2.doc:101111/anec.12320.

48. Inglis, S. C., Clark, R. A., Cleland, J. G., \& Cochrane Systematic Review Team., 2011. Telemonitoring in patients with heart failure. $N$ Engl J Med 364(11):1078-1080 
49. van der Wal MH1, van Veldhuisen DJ, Veeger NJ, Rutten FH, Jaarsma T. Compliance with non-pharmacological recommendations and outcome in heart failure patients. Eur Heart J. 2010;31(12):1486-93.

50. Santaularia N, Jaarsma T. Motivational factors for exercise in cardiac patients? A literature review. Eur J Prev Med 2013; 1(1): 1-19

51. World Health Organization. WHO Adherence to long-term therapies: evidence for action. WHO 2003: 10/11/2010.

52. Piotrowicz E, Piotrowicz R. Cardiac telerehabilitation: current situation and future challenges. Eur J Prev Cardiol. 2013;20(2 Suppl):12-6. 
Table 1 Methods of telemonitoring

\begin{tabular}{|c|c|}
\hline Devices & Object of monitoring \\
\hline Telephone, mobile phone, Internet & $\begin{array}{l}\text { Symptoms: } \\
\text { - dyspnea } \\
\text { - breathlessness } \\
\text { - peripheral oedema } \\
\text { - fatigue } \\
\text { - chest pain } \\
\text { - palpitations } \\
\text { - syncope } \\
\text { - psychological status }\end{array}$ \\
\hline External devices & $\begin{array}{l}\text { Parameters: } \\
\text { - ECG (heart rate, conduction disturbances, arrhythmias, ST segment } \\
\text { changes, silent ischaemia) } \\
\text { - blood pressure } \\
\text { - body weight } \\
\text { - saturation } \\
\text { - respiration } \\
\text { - lab test (i.e. glucose, INR etc) }\end{array}$ \\
\hline $\begin{array}{l}\text { Cardiovascular implantable } \\
\text { electronic devices (CIEDs) }\end{array}$ & $\begin{array}{l}\text { Parameters: } \\
\text { - mean heart rate over } 24 \mathrm{~h} \\
\text { - heart rate at rest } \\
\text { - patient activity } \\
\text { - frequency of ventricular extrasystoles } \\
\text { - heart rate variability } \\
\text { - right ventricular pacing impedance } \\
\text { - painless shock impedance }\end{array}$ \\
\hline $\begin{array}{l}\text { Haemodynamic implantable } \\
\text { electronic devices }\end{array}$ & $\begin{array}{l}\text { Parameters: } \\
\text { - pulmonary artery pressure } \\
\text { - left atrial pressure }\end{array}$ \\
\hline
\end{tabular}


Table 2 Factors influencing telerehabilitation safety.

-the correct risk stratification of patients for rehabilitation

-the contraindications to exercise training

-concomitant HF device therapy (ICEDs) and the regulation which states that the training heart rate must be 10-20/min below the ICD intervention threshold

-patients with initial educational sessions (self-evaluation)

-the tailoring of training for each specific patient

-efficient day-to-day qualification to an appropriate training session using a special training consent procedure before each training session, after initial evaluation of the clinical symptoms and resting ECG by telemonitored team at the monitoring center

-the rating of perceived exertion and ECG immediately after or during each training session

-exercise acceptance by patients combined with their willingness to perform it

-the presence of a caregiver who accompanies the patient during exercise and who would be able to provide first aid and call professional medical help in case of emergency 
Table 3 Advantages and limitations of telerehabilitation

\begin{tabular}{|c|c|c|}
\hline & Strengths & Limitations \\
\hline Patient issues & $\begin{array}{l}\text { Familiar surroundings: exercise at } \\
\text { home, on one's own, at one's own } \\
\text { pace and at a chosen time } \\
\text { Real time video conferences (advanced } \\
\text { telemonitoring systems) } \\
\text { Ability to continue rehabilitation in } \\
\text { case of problems with adhering to } \\
\text { hospital-based program } \\
\text { Elimination of transportation related } \\
\text { issues (time and cost saving) } \\
\text { Furthering patient independence in } \\
\text { performing everyday tasks }\end{array}$ & $\begin{array}{l}\text { Technological skills /trouble } \\
\text { shooting } \\
\text { Missing face-to-face contact } \\
\text { with medical staff and other } \\
\text { patients (simple telemonitoring } \\
\text { systems) }\end{array}$ \\
\hline Professional issues & $\begin{array}{l}\text { Ability to treat more patients } \\
\text { Ability to combine with telemonitoring } \\
\text { Increased control of patient adherence }\end{array}$ & $\begin{array}{l}\text { No 'hands on' real time contact } \\
\text { (immediate medical attention } \\
\text { unavailable in case of } \\
\text { emergency) } \\
\text { Education classes more difficult } \\
\text { via telephone }\end{array}$ \\
\hline Health care system & $\begin{array}{l}\text { New equipment and technology } \\
\text { becoming rapidly available } \\
\text { Low cost, depending on its use } \\
\text { (replace vs. add to existing care) }\end{array}$ & $\begin{array}{l}\text { Reimbursement } \\
\text { Lack of legal principles } \\
\text { Lack of comprehensive } \\
\text { telemedical integration system }\end{array}$ \\
\hline
\end{tabular}

